\title{
Flanqueando el procesualismo y posprocesualismo: Arqueología, teoría de la complejidad y la filosofía de Gilles Deleuze
}

\author{
Beyond processualism and postprocessualism: \\ archaeology, complexity theory, and the philosophy of Gilles Deleuze
}

\author{
Pablo Alonso González \\ Departamento de Arqueología, Universidad de Cambridge \\ Downing Street. Cambridge CB2 3DZ. Reino Unido \\ pa332@cam.ac.uk
}

Recibido: 14-04-2012

Aceptado: 12-09-2012

\begin{abstract}
RESUMEN
La aplicación de la filosofía de Gilles Deleuze en el ámbito arqueológico permite superar la dicotomía entre procesualismo y posprocesualismo, abriendo la puerta a un pensamiento diferente. Su teoría facilita la recepción de las ideas de las diferentes teorías de la complejidad, gracias a su carácter realista y a la priorización de la ontología sobre la epistemología. Este movimiento nos permite superar el giro simétrico y las distintas oposiciones binarias que subyacen al pensamiento arqueológico, como estructura-proceso, sujeto-objeto, verdad-valor o identidad-diferencia. A la vez, intentamos replantear algunas esferas de la disciplina arqueológica a través de una crítica de su conformación interna y externa, con lo que intentamos abrir el espectro de interpretaciones arqueológicas posibles.
\end{abstract}

Palabras Clave: Deleuze. Teoría de la Complejidad. Procesualismo. Posprocesualismo. Simetría.

\begin{abstract}
The paper suggests that the politically informed complex philosophy of Gilles Deleuze can enable archaeologists to overcome the dichotomy between processualism and postprocessualism, opening the door to different kinds of archaeological thinking. His philosophy facilitates the reception and translation into the social sciences of the ideas coming from complexity theory, thanks to his realist stance and his prioritization of ontological over epistemological concerns. This move allows us to overcome the 'symmetric turn' and the different dichotomies underlying current archaeological thought, such as structure-process, subject-object, identity-difference, truth-value, or self-other. Finally, the paper rethinks some areas of archaeological theory through a critique of the internal and external conformation of the discipline, aiming at opening the spectrum of available interpretative frameworks.
\end{abstract}

KEY words: Deleuze. Complexity Theory. Processualism. Postprocessualism. Simmetry.

Sumario: Introducción. Deseo, Poder. Ser, diferencia. Verdad, realismo trascendental. El cambio, exo y endo-referencia, causalidad y emergencia. Estructura/"agencia", producción del sujeto. Multisubjetividad, interferencia recíproca. Complejidad. Pensar lo social, agenciamientos. Conclusión. 


\section{Introducción ${ }^{1}$}

"Los libros contra el estructuralismo [...] no tienen estrictamente ninguna importancia; no pueden impedir que el estructuralismo tenga una productividad que es la de nuestra época. Ningún libro contra lo que sea tiene nunca importancia; sólo cuentan los libros "para' algo nuevo, y que saben producirlo" (Deleuze 1984: 599).

El presente artículo desarrolla una propuesta teórica constructiva basada en la filosofía de Gilles Deleuze y Félix Guattari y su conexión con la teoría de la complejidad. Somos conscientes que se trata de dos temáticas a priori poco apetecibles para el público arqueológico. Intentaremos ofrecer así este texto no como una guía estricta sino como una caja de herramientas de la que arqueólogos puedan extraer intuiciones y propuestas. Debido a la complejidad y amplitud de la filosofía deleuziana se han marginado cuestiones clave: el cuerpo (Massumi 2002), el tiempo y la memoria (Mahler 2008) y la política (Patton 2000). Algunos echarán en falta una revisión o un enfrentamiento más directo con la literatura teórica arqueológica. Creemos sin embargo que al construir una propuesta concisa las diferencias con otras perspectivas deberían surgir por disyunción de pareceres y no por oposición directa.

Siguiendo una intuición del arquitecto Zaera-Polo (2008) que podría extrapolarse a otras ciencias sociales, la arqueología académica se encuentra atrapada en un bucle bidireccional. Los procesuales afirman la autonomía de la arqueología y buscan la mejora de sus procedimientos, a la vez que limitan el potencial de transformación social de la disciplina. Los posprocesuales asumen el giro lingüístico, la incidencia de condicionantes sociopolíticos externos y encarnan roles cercanos a la representación política e identitaria, topando finalmente con el límite último del relativismo posmoderno en ciencias: ¿cómo evaluar y demarcar la verdad? Es lugar común en arqueología querer superar ambos extremos (Smith 2006), que en la práctica sólo han existido como polos abstractos o testaferros a los que criticar o apoyar teóricamente. Partimos de estos planteamientos:

1. Se está produciendo un retroceso generalizado de las conquistas del posprocesualismo en paralelo a un reaccionario retorno al refugio del "buen trabajo de campo" positivista. Un repliegue relacionado con la asunción del posmodernismo filosófico y la interpretación en arqueología y derivado del choque frontal con la cuestión de la verdad y sus formas de demarcación. Sin embargo, ni el retorno al positivismo ni la prolongación del posprocesualismo permiten dar respuesta a las demandas del público ni a los retos que la investigación social afrontará en los próximos años (e.g., reduccionismos explicativos a partir de la neurociencia social, demanda social de narrativas comprensibles, etc.).

2. La Arqueología Simétrica no ha proporcionado una alternativa válida al tratarse tan solo, en contra de lo que dicen sus proponentes, de un giro epistemológico. Por ello, se intuye una tendencia al acercamiento por parte de algunos arqueólogos a las teorías de la complejidad (TC). Sin embargo, este paso no es sencillo debido a:

a) Variedad de TC existentes (ver Reynoso 2006). Los procesualistas suelen acercarse a unas (e.g. Garnsey y McGlade 2006) que denominamos "románticas" (e.g. Morin 1994), y creemos que los posprocesualistas deberían acercarse a otras denominadas "barrocas" (ver más abajo).

b) Es necesario un giro ontológico para que se produzca el acoplamiento entre arqueología y teoría de la complejidad. En la mayoría de las ontologías de las ciencias sociales actuales, y por derivación de la arqueología, subyace una concepción dialéctica derivada de Hegel y Marx, y canalizada por el psicoanálisis de Freud-LacanŽižek y la sociología de Durkheim. Un pensamiento dicotómico o dialéctico difícilmente puede convivir con un pensamiento complejo, a no ser que este se utilice retóricamente como metáfora o recurso lingüístico, un problema que se evidencia en el imposible intento de la arqueología simétrica de conjugar la dialéctica hegeliana con la simetría de Bruno Latour.

3. A través de Deleuze, filosofía y arqueología pueden acoplarse con una TC concienciada políticamente que permita superar los retos planteados por los reduccionismos científicos (e.g. teorías neuronales). En paralelo, arqueólogos de todas las tendencias pueden volver a dialogar evitando el círculo vicioso de la cuestión de la representación o el sempiterno litigio funcionalismo/hermenéutica; realismo/posmodernismo, etc. Finalmente, las energías y recursos empleados en la defensa de las fronteras disciplinares de la arqueología podrían emplearse en un encuentro directo y positivo con la filosofia, en lugar de continuar la retrógrada búsqueda de un pensamiento "propiamente arqueológico". Pese a no poder tratar todos estos temas aquí, Deleuze permite abordar tanto cuestiones "internas" (determinación de la naturaleza de la ciencia) como "externas" (conexiones con lo sociopolítico y económico) de la arqueología.

\section{Deseo, Poder}

Lejos de ser un pensador posmoderno, el pensamiento de Deleuze permite acomodar los resultados obtenidos a, o pensar a través de, la TC (DeLanda 2004). Resumiendo los planteamientos de los diversos estudiosos de su obra se concluye que su postu- 
ra es de un materialismo naturalista (Rosanvallon y Preteseille 2009: 32) que deja de lado divisiones modernas como naturaleza/cultura, material/humano, estructura/agencia, etc. Su obra persiguió la demolición del psicoanálisis, invirtiendo su postulado negativo esencial: el deseo no se dirige siempre hacia un otro, no es una carencia, sino que se trata de un impulso básicamente positivo: "pura productividad positiva que debe ser codificada por el socius, la máquina de producción social" (Viveiros de Castro 2010: 99). La carencia es un producto secundario del deseo bajo ciertas condiciones (Rosanvallon y Preteseille 2009: 31). Este es un matiz que separa a Deleuze de Foucault: para él el deseo -el impulso o voluntad de establecer nuevas conexiones en el mundo- es anterior al poder (Biehl y Locke 2010; Deleuze y Lapoujade 2006: 125). Siguiendo a Spinoza, el poder sería la forma que toma el deseo cuando vuelve sobre sí mismo para reforzar sus conexiones y logros (Brown 2009: 107). En este sentido, las interpretaciones arqueológicas de formaciones identitarias tanto individuales como grupales habrían de pasar de ser fundamentalmente psicoanalíticas (i.e., la identidad del individuo se construye por oposición al "otro" en su búsqueda de suplir sus "carencias" psicológicas), a ser concebidas como construcciones variables que no precisan de otro para afirmar su alteridad y particularidad.

\section{Ser, diferencia}

Una de las cuestiones que ha provocado el "cisma" en arqueología es la ontología anti-realista asumida por los posprocesuales (ver Domínguez Rodrigo 2008). La ontología-¿qué es lo que es o existe?- es el conjunto de entidades que una persona afirma que forman la realidad. Podríamos distinguir tres grandes posicionamientos al respecto:

1. La realidad no existe independientemente de la mente humana: ontologías basadas en entidades mentales transcendentes o representaciones sociales y lingüísticas que delegan un gran peso a la epistemología, ¿qué puedo conocer? La filosofía kantiana, el existencialismo y algunas corrientes hermenéuticas se sitúan en este ámbito, en el que también podemos incluir la fenomenología de Tilley (1994).

2. La realidad cotidiana existe con independencia de la mente, pero se duda de las cosas no-observables: electrones, causalidad física.

3. La realidad, tanto la observable como la no observable, es totalmente autónoma de la mente. Esta posición abandona el antropocentrismo que las dos previas presuponen, y es abrazada por Deleuze y posteriormente por la Teoría-Actor-Red. También el realismo crítico podría incluirse en esta categoría (e.g. Domínguez Rodrigo 2008).

Deleuze busca dar unas nuevas bases fundacionales a la filosofía y las ciencias sociales (Hardt 1993: XV). Su idea básica es que el Ser funciona por naturaleza como pura diferencia en constante variación o Devenir (en lugar del estático Ser-en-elmundo Heideggeriano/fenomenológico). Abandona así los fundamentos ontológicos occidentales, cuyas cuatro principales categorías -identidad, semejanza, oposición, analogía- y tareas -reconocer, clasificar, juzgar - han ido siempre unidas al pensamiento del dominador y el orden establecido (Massumi 1992: XI). Lo no mensurable, no categorizable, o esencializado como "diferente" va siempre contra el funcionamiento estatal (Hardt y Negri 2000).

La teoría social, que sirve de base a las interpretaciones arqueológicas, ha sido mayoritariamente cómplice de este status quo al propagar estas categorías a todos los ámbitos, con el positivismo funcionando como "profecía autorrealizada" que conformaba la materia del mundo a sus moldes preconcebidos. La lógica identitaria " $x=x=n o y$ " fundamenta así la teoría social desde Hegel y Marx. Así funcionan el interaccionismo (identidad personal como síntesis de la otredad), la fenomenología (el mundo vital del individuo como unidad, lo otro como representación) y las teorías que asumen la sociedad como intercambio, ya que presuponen una equivalencia universal de valores (Bogard 1998). Es por ello que Deleuze conceptualiza el origen de la inequidad social a partir del concepto de "deuda" y no del "intercambio" como postulaba el estructuralismo (Viveiros de Castro 2010), al que Lingis (1994) acusa de basarse en un modelo de comportamiento humano en el que los valores son intercambiables y circulan en sociedad según una ley de equivalencia: mujeres (Lévi-Straus), mercancías (Marx), castigos y premios (Homans) o dinero y poder (Parsons). Para Deleuze la sociedad es esencialmente un instrumento de captura y articulación de las voluntades y deseos sociales (Lordon 2006). Así "la sociedad no es un medio de intercambio en el que lo esencial radicaría en circular o en hacer circular; la sociedad es un socius de inscripción donde lo esencial radica en marcar o ser marcado" (Deleuze y Guattari, 1985: 148).

Deleuze no concibe las transformaciones sociales como representaciones sino como "desterritorializaciones" o cortes que liberan energías permitiéndolas recombinarse en formas nuevas. El capitalismo no se conceptualiza como un organismo de represión de clases o individuos, sino como un ingente ente desterritorializador. La cuestión esencial se convierte en cómo los nuevos "agenciamientos" emergidos tras la desterritorialización 
organizan y capturan las energías liberadas: el capitalismo funcionaría así como una gigantesca maquinaria de captura de energías y materias (Lordon et al. 2010). Las nuevas codificaciones que surgen no producen identidades o resuelven contradicciones, sino que multiplican superficies y variaciones, como los fractales complejos. " $x=x=$ no $y$ ", pasa a ser " $a+b+z+y \ldots$... ad infinitum.

Así, la diferencia es "también comunicación, contagio de heterogéneos...contaminación recíproca de los puntos de vista...La exclusión de predicados es sustituida por la comunicación de acontecimientos...Los puntos de vista no divergen sin implicarse mutuamente... La idea deriva del concepto de multiplicidad ${ }^{2}$, según el cual una pura diferencia solo tiene con otras una relación de diferencia, pero no se afirma precisamente como tal sino a distancia de las otras" (Zourabichvili, cit. en Viveiros de Castro 2007: 100). Esta noción subyace al concepto de perspectivismo desarrollado por Viveiros de Castro (2011), las conexiones parciales de Strathern (2004) o las personas fractales de Wagner (1991). Este último explicaba refiriéndose a sus encuentros con los Daribi que "el modo en el que ellos no me comprendían no era el mismo modo en el que yo no les comprendía" (cit. en Viveiros de Castro 2007: 102): la diferencia nunca es la misma en los dos sentidos (Zourabichvili 2003). De aquí deriva el concepto deleuziano de síntesis disyuntiva: dos puntos de vista no han de oponerse necesariamente, sino que se contagian recíprocamente para producir una nueva relación de presuposición recíproca que no tiene por qué ser simétrica o una síntesis negativa hegeliana, ni el resultado de una causalidad linear o un modelo trascendental kantiano.

Desde esta concepción ontológica de la diferencia podemos criticar los planteamientos de la arqueología simétrica (Shanks 2007): esta propone una simetría epistemológica, lo cual permite mantener la distancia entre investigador e investigado, y reproducir las geografías desiguales de poder, raza, clase y género. Una simetría epistemológica, que busque dar la misma voz a distintos actores en la investigación y que identifica antagonismos y problemas "en el afuera", no transforma la posición de poder del investigador occidental ni el campo de lo estudiado. Más bien reproduce el colonialismo arqueológico que objetualiza al otro, nominándolo, segmentándolo en partes para su estudio, e introduciéndolo en nuevas redes de conocimiento y distribución que benefician al propio investigador pero no al/lo investigado (Haber 2011). Una arqueología deleuziana y decolonial es directamente política, ya que asume su domicilio de investigación y trabaja al lado de movimientos sociales de forma horizontal: no localiza los antagonismos en el afuera sino que opera con ellos y los habita. Así, el "conocimiento" no es algo que el investigador obtiene gracias a una supuesta distancia objetivadora para con lo investigado, una representación más o menos fiel de la realidad del pasado, sino una producción nueva de valores, verdades y creencias que se añaden al mundo y operan en él.

\section{Verdad, realismo trascendental}

Deleuze no es por lo tanto un relativista sino un perspectivista. No propugna una relatividad de la verdad sino una "verdad de la relatividad" (Bogard 1998: 59); "el punto de vista no varía con el sujeto... al contrario, es la condición bajo la cual un eventual sujeto capta una variación" (Deleuze 1989: 31), o lo que es lo mismo, no hay puntos de vista sobre las cosas sino que los seres y las cosas son puntos de vista. La cuestión no es saber si el sujeto es capaz de conocer la verdad (epistemología) o de si la verdad existe, sino de conocer sus engranajes, su organización, límites y forma de construcción (Fox y Ward 2008). De este modo, una idea expandida de verdad ha de ser abrazada, donde criterios de relevancia e interés prevalezcan sobre una imagen de la arqueología derivada del positivismo tradicional que sólo busque analogías, identidades y la adecuación de una representación o un concepto a una realidad o a un experimento (Stengers 2000: 160).

Siguiendo el llamamiento de Moro (2007) a una crítica de la externalidad en arqueología, creemos en primer lugar necesario situar la cuestión de "verdad" en términos de producción y no en oposición al concepto de "valor" (ver Fernández Martínez 2006). Si seguimos la máxima anti-trascendental de Deleuze, no podemos concebir la verdad como una idea platónica, allá fuera, esperando a ser revelada. A primera vista, nuestras evaluaciones -científicas o filosóficas- parecen estar sustentadas por valores o principios como la "verdad". Sin embargo, afirma Deleuze, en realidad son los valores o principios los que presuponen evaluaciones, que funcionan como "perspectivas" que sustentan y de las que deriva el propio valor (Mahon 1992: 83). Por lo tanto, son la voluntad (Nietzsche) o el deseo (Deleuze) - es decir, las formas de vida - los que se encuentran en el origen de la formación de las evaluaciones que conforman los valores como el de "verdad" (Deleuze y Artal 1971) o "verdad-objetiva" en el caso del positivismo: la verdad no viene inducida por el valor, sino que es una producción derivada del deseo (Citton y Lordon 2008).

Distintas actitudes hacia la verdad implican distintas formas de entender una arqueología crítica. 
Generalmente, los arqueológos "consideran que oponerse a las narrativas oficiales implica desvelar todos los datos disponibles y... producir narraciones alternativas y más completas" (González-Ruibal 2008: 20). Esta concepción de la crítica de derivación ilustrada-chomskiana considera posible el establecimiento de verdades universales a partir de la existencia de una "esencia" compartida entre los seres humanos. Como se evidenció en el debate televisivo entre Chomsky y Foucault (1974), las ideas de ambos son opuestas con respecto a la verdad. La idea de verdad de Deleuze se acerca a la de Foucault, siendo de carácter "pesimista" (Žižek 2004), a la vez que constructivista: la verdad no está "ahí fuera" para ser revelada, sino que se construye. Lo que importa entonces son la cuestiones micropolíticas: cómo se construye la verdad, desde qué domicilio de investigación, con qué actores sociopolíticos se trabaja, a favor de qué, etc. Usando la imagen deleuziana quizás más conocida, el arqueólogo forma un rizoma entre las representaciones de su registro del pasado, sus interpretaciones, domicilio de investigación, bagaje cultural, medios científico/financieros y relaciones con actores sociopolíticos. El carácter alternativo/crítico de su actuación no deriva entonces de desvelar datos que representan "la verdad" u "otra verdad", sino de la construcción de un régimen de verdad (i.e., un sistema de valores) que ofrezca formas de alteridad y diferencia en el pasado, oponiéndose en el presente a las máquinas de poder para las que trabaja la ciencia positivista oficial.

El trabajo de Domínguez Rodrigo (2008) servirá para exponer nuestro punto de vista. Según él, hay muchos "arqueólogos partidarios de reconstruir el pasado (realistas) y no sólo interpretarlo (relativistas), la realidad de ese pasado es un hecho y su aprehensibilidad sólo se posibilita mediante paradigmas que establecen un puente entre el mismo y el presente" (Ibíd.: 219). En su artículo presenta el realismo crítico (reconstruir, deducir, explicar) en oposición al constructivismo social (interpretar, deconstruir, entender), oponiendo la "verdad" al "relativismo" que renuncia al concepto de verdad: fuera del realismo crítico sólo quedan el positivismo ingenuo (inducir) y lo posmoderno anti-realista. Exponemos varias reflexiones a propósito:

- El constructivismo se equivoca al buscar significados e interpretar los restos del pasado: el significado "objetivo" de un signo no puede ser considerado idéntico al significado "subjetivo" con el que fue concebido.

- El realismo crítico Bhaskariano es probablemente la ontología más desarrollada hasta el momento en arqueología gracias a su uso del mé- todo trascendental, el privilegio de ontología sobre epistemología, su énfasis en mecanismos en lugar de leyes, en sistemas abiertos y no cerrados, y su materialismo implícito. Sin embargo, desde un punto de vista deleuziano, falla por su esencialismo, su énfasis en buscar los límites del conocimiento en lugar de "objetos reales", y su interpretación de cuestiones trascendentales en términos empíricos (ver Norrie 2010).

- Así, constructivismo y realismo en realidad mantienen la falacia del antropocentrismo en su proyección de imágenes científicas. Para Deleuze es fundamental la búsqueda de las condiciones reales de generación de un objeto, su contexto de "individuación" (ver Toscano 2006). El conocimiento no implica "reconstruir" ni "interpretar", sino "construir" algo nuevo a partir del registro arqueológico. No abandonamos el criterio de verdad sino que lo concebimos como un proceso emergente más del que hay que dar cuenta. Dudamos por lo tanto de la posibilidad afirmada por Domínguez Rodrigo de reconstruir el pasado: más bien habría que hablar de construir un pasado nuevo.

Creer en la posibilidad de reconstruir el pasado equivale a afirmar la existencia de un pasado "ahí afuera" que puede ser descubierto y representado: sólo necesitamos una epistemología correcta para que nuestro conocimiento nos permita "descubrir" esa realidad (ver Latour 1984). Esta afirmación de un pasado real por descubrir no sólo se emplea en contra del relativismo posprocesualista, sino también en la defensa de una arqueología "dura" opuesta a la pseudoarqueología (e.g. Fagan 2006) o de su concepción como cultura popular (ver debate Kristiansen/Holtorf en Kristiansen 2008). Esta creencia en la existencia de un investigador "aquí", que objetualiza un pasado "ahí afuera" mediante un salto mortal epistemológico ha sido deconstruida por Latour (2007). Para él, nunca se produce esa objetualización epistemológica ya que la construcción de conocimiento es siempre un ensamblaje de múltiples elementos convergentes: el arqueólogo, su contexto sociopolítico y económico, su representación del pasado, sus teorías preferidas, etc. Basándose en la exposición del Museo de Historia Natural de Nueva York en la que se presentaba la historia de la evolución de los caballos en paralelo a la del conocimiento científico sobre los mismos, Latour (2007) argumenta que todo conocimiento es ontológico al formar parte de la realidad de cada época. Así, las distintas visiones de la Edad del Hierro (o de los caballos) a lo largo del tiempo, desde el celtismo histórico-cultural hasta planteamientos críticos recientes, forman parte del mundo en el que se producen y difunden, estructuran el pensamiento de las personas 
(producen subjetividad) y tienen efectos políticos: no son representaciones epistemológicas fallidas o certeras que puedan ser clasificadas en una escala de progreso hacia una mayor perfección.

Una arqueología que afirma la existencia de un pasado "ahí fuera", aún por descubrir a través de una epistemología concreta, construye una imagen del pasado que permite su esencialización y apropiación política: un pasado ordenado cronológicamente, que evoluciona linealmente mediante una causalidad eficiente y a partir de una primera causa, y que cimienta la base del tiempo teleológico de las Historias oficiales del poder (Martin-Jones 2006). Una arqueología deleuziana parte del presente para remontarse hacia atrás en el tiempo y desvelar las múltiples imágenes del pasado cuya "verdad" construida ha de ser críticamente examinada, mostrando que el desarrollo histórico es contingente, variable y discontinuo.

\section{El cambio, exo y endo-referencia, causalidad y emergencia}

Las categorías deleuzianas no pueden entenderse en términos tradicionales de escala. Así, sus conceptos de análisis social "molar/molecular" no refieren a dos escalas "grandes" o "pequeñas", sino a una diferencia irreducible entre la física y la mecánica cuántica. La física se basa en el principio de separación espacio-temporal (extensiva) de la teoría de la relatividad, que sirve para neutralizar los sistemas de referencia locales permitiendo su transformación en leyes generales válidas globalmente (positivismo/exo-referencia). La mecánica cuántica determina su realidad por el principio de superposición (intensiva) sin necesidad de referencias externas (endo-referencia) (Rosanvallon y Preteseille 2009: 119). Se perfilan aquí dos niveles de análisis cuya semejanza con los problemas afrontados por los posicionamientos "emic/etic" y la matización/superación de los principios universalistas aplicados por los estructuralistas en antropología y arqueología resultan evidentes. ¿Podríamos pensar en arqueología sin la presuposición de modelos previos? ¿Sin utilizar analogías y similitudes, afrontando cada cultura pasada como diferente en sí misma? Si este paso adelante es complicado en antropología (Hamilton y Placas 2011), aún lo es más en arqueología, la ciencia de las analogías (Cogotas II = Bronce Final, etc.). Pero, "por lo menos, ganamos el derecho a especular en esa dirección" (Viveiros de Castro 2007: 101).

Estudiar culturas como singularidades implica hablar de un continuum, una realidad cambiante sin causas finales externas a la realidad misma que cambia (e.g. evolucionismo, ideología individualista o de progreso, etc.) y que la dirijan. Entonces, si queremos concebir el cambio como algo diverso a la negación, ruptura, desviación o subversión (Massumi 2002: 70), es importante concebir los términos (individuos, colectivos) como entes que son capaces de establecer relaciones parciales, múltiples y variadas dentro de la esfera social. En realidad, "se trata de saber si todas las relaciones posibles de un ser con los demás están primitivamente encerradas en su naturaleza intrínseca y entran en su esencia" (Lazzarato 2006). En filosofía y teoría social se asume mayoritariamente que los términos preceden a la constitución de las relaciones, de modo que todo se encuentra ya predeterminado y se entra en círculos viciosos hermenéuticos como el del huevo y la gallina. De ahí la frase apropiada por Deleuze de la mitología Dogón: "el mundo es un huevo" (1988a: 338 ), con la que se refiere a los procesos intensivos y moleculares acaecidos siempre previamente a la emergencia de las formas extensivas y molares de nuestra experiencia cotidiana. El principio es sencillo: si asumimos la causalidad de la física de raíz aristotélica (final, formal) y el principio pragmatista de que las relaciones entre agentes se presuponen en sus términos antes de entrar en relación, entonces tiene que haber una causa primera, trascendental, que dé sentido a nuestra realidad. Contra esta posición, la filosofía deleuziana abraza la inmanencia y niega la transcendencia para dar cuenta del cambio y la emergencia de lo nuevo a partir de causalidades eficientes y relaciones exteriores a sus términos. Asume así la imposibilidad de afrontar la complejidad a partir de la causalidad de la física (Prigogine y Stengers 1984).

La causalidad física, asumida mayoritariamente por el positivismo arqueológico, lleva necesariamente al establecimiento de leyes universales que permiten prever patrones de comportamiento, desde el ejemplo clásico de colisiones entre moléculas o bolas de billar a los modelos predictivos de poblamiento elaborados mediante tecnología SIG: no hay sorpresas ni producciones novedosas. En este universo, la vida y el movimiento son propiedades de la materia que se "transmiten" desde el pasado a partir de leyes fijas. La supuesta reconstrucción arqueológica del pasado no puede ser así más que la representación de una serie de tiempos e imágenes conformes a las leyes que gobiernan el funcionamiento de la naturaleza y, por extensión, de lo social. Además, esta "reconstrucción objetiva" ha de ser fenomenológica al ser un individuo quien la realice desde su perspectiva observadora. En su lugar, Deleuze busca conocer los distintos ritmos, tiempos y velocidades que emergen en formas de autoorganización biológicas, físico-químicas y sociales. 
Así, no pretende realizar descripciones fenomenológicas, sino cartografiar las "restricciones virtuales que operan dentro de los sistemas materiales y que hacen que los sistemas tiendan a la homeostasis... o a la metamorfosis. Tanto la homeostasis como la metamorfosis operan a través de diversas escalas espacio-temporales de producción y reproducción que llevan a que ciertos sistemas se diferencien unos de otros" (Groves 2009).

En este sentido, una arqueología deleuziana puede derivar sus modelos de las ciencias duras, pero no necesariamente de la física newtoniana determinista. Más bien, de una concepción química de la causalidad que permita dar cuenta de la emergencia: el agua posee propiedades que no se encuentran en sus componentes (oxígeno e hidrógeno). Que propiedades y capacidades nuevas emerjan de relaciones causales trae consecuencias para la explicación científica: ya no es posible mantener, como en la física, que explicar se reduce a la deducción a partir de principios o leyes generales que transfieren una verdad de lo genérico a lo particular. La novedad química no es tal en el sentido de que "el agua nunca haya existido", sino que se refiere al surgimiento de algo original (agua líquida) que no se encontraba entre las entidades funcionando como causas (oxígeno, hidrógeno) (DeLanda 2011: 2). Así, lo que Deleuze denomina escala molecular son precisamente los "agenciamientos" donde los cambios son intensivos (variación climática, organización interna, posibilidad de movimiento, composición química...), mientras en la escala molar - la de las agencias técnicas, la familia o las instituciones- los cambios son extensivos (volumen, masa, estructuración diversa...) y los comportamientos emergentes ${ }^{3}$.

Esta concepción de la realidad y de lo social deleuziana permite acomodar los retos planteados por los reduccionismos científicos provenientes del ámbito de la neurocultura. Este conjunto de teorías amenaza las formas de explicación/interpretación antropológica (de la que la arqueología deriva sus modelos interpretativos) y la subsistencia de la antropología sociocultural como tal. La doctrina neuronal considera que las propiedades emergentes de lo social y sus procesos (comportamiento, actitudes, emociones, etc.) pueden ser explicados por fenómenos a nivel micro, en otras palabras, que las estructuras sociales derivan de procesos y propiedades a nivel cerebral. Pese a ser ya la perspectiva mayoritaria en el ámbito de las ciencias naturales, las ciencias sociales y humanidades no le han sabido dar una respuesta crítica más allá de una reacción anti-cientifista (Martin 2010). La ontología deleuziana abre una salida al problema a través de su vinculación a la teoría de la comple- jidad, al asumir la importancia de procesos micro (moleculares), pero estableciendo una interacción entre estos y los procesos macro (molares) en la que ambos se interdeterminan sin caer en un reduccionismo ni de un lado ni de otro. Su ontología cuadra además con desarrollos en el propio ámbito de la neurociencia compleja que muestran cómo el cerebro y sus procesos (e incluso su composición química y estructuración) también están condicionados por el mundo exterior y sus estructuras molares (Mora inédito). Al igual que los genes y el individuo, el cerebro como fenómeno emergente se desarrolla en relación con disparadores externos dados por el ambiente socio-natural. Deleuze nos permite así mantener una autonomía explicativa/ interpretativa en antropología/arqueología sin caer en una negación simplista de los reduccionismos biológicos y neuronales que cada vez cuentan con más apoyo financiero y académico.

\section{Estructura/"agencia", producción del sujeto}

Este es un problema fundamental en arqueología, no sólo a la hora de plantear los términos de la propia investigación y sus objetivos, sino también al interpretar en el registro las dinámicas de cambio social o el rol de los individuos. Por ejemplo, cuando Shanks (versión simétrica) lidia con la cuestión reproduce la dicotomía estructura/individuo:

“...la estructura social es al mismo tiempo el medio y el resultado de prácticas (individuales) motivadas. Las personas hacen historia, pero bajo circunstancias heredadas sobre las cuales no tienen control inmediato" (Shanks 2007: 292).

La concepción de sistemas sociales como estructuras ha estado siempre presente en la interpretación de las ciencias sociales, ya que su funcionamiento se puede reducir a leyes y reglas. Esta situación deriva evidentemente del positivismo, que utilizaba la mecánica clásica como modelo científico al que las ciencias sociales debían amoldarse. Aunque también hay otros muchos modelos de estructura: la funcionalista/naturalista de Parsons y la Teoría General de Sistemas, la Teoría Autopoiética de Luhman, el estructuralismo de Lévi-Strauss y sus variantes posmodernas. Por otro lado, el énfasis en la "agencia" - la capacidad de los sujetos para crear lo nuevo o actuar en el mundo- se vincula normalmente a posicionamientos hermenéuticos humanistas que afirman la irreductibilidad del "entender" al "explicar", concibiendo la agencia casi como un acto de "resistencia" del individuo ante el determinismo de las estructuras (del poder, se sobreentiende). 
Deleuze puede considerarse como un funcionalista que en lugar de considerar como estructura tan solo sistemas homeoestáticos (en constante búsqueda del equilibrio), amplía su conceptualización de estructura a sistemas abiertos y con capacidad autoorganizativa. También es naturalista, pero incluye en la naturaleza sustancias tanto animadas como inanimadas, idea que Latour importará a posteriori junto con la de agenciamiento (Harman 2009). Sin embargo, Latour ha incidido excesivamente en la unificación de lo orgánico/inorgánico, cuando en realidad la división relevante a nivel analítico es la de molar/molecular (Bowker 2009), como bien demuestran los avances en neurociencia social.

Por el contrario, Deleuze rompe con las estructuras de Lévi-Strauss y los posmodernismos al incluir la cuestión del lenguaje y el significado como una semiótica más dentro de las varias que pueblan el mundo, y no como la totalidad que enmarca el resto de relaciones. Los conjuntos de significados que remiten a otros significantes en cadenas de significación/interpretación (e.g. los primeros estudios simbólicos de Hodder 1982), toman un nuevo rol al confrontarse con la teoría de la complejidad deleuziana, según la cual ciertos sistemas, al superar umbrales críticos, parecen "sentir" las diferencias en su entorno que disparan procesos de auto-organización (Bonta y Protevi 2004: 4). Aquí los "signos" son umbrales percibidos por ciertos sistemas que "no sólo ocurren más allá del ámbito de lo humano y lo orgánico, sino que esencialmente disparan transformaciones materiales...El 'significado' de un signo es la medida de la probabilidad de disparar un proceso material determinado" (Ibíd: 4). En resumen: cultura y economía, producción y significación, se encuentran íntimamente unidos e interdeterminadas: un cambio en representaciones figuradas cerámicas refleja formas de producción a la vez que las altera (es decir, se trata de un proceso de emergencia donde aparece la "novedad" como tal).

Por su parte, Guattari profundizó en la crítica al estructuralismo en sus trabajos individuales. Althusser, Lévi-Strauss y especialmente Lacan fueron objeto de crítica al considerar su búsqueda de patrones subyacentes a la cultura, al comportamiento y a la psique como una forma de conocimiento esquemática, reduccionista, universalista y atrapada en el lenguaje. Al "inconsciente como lenguaje" lacaniano, Guattari propone un maquinismo generalizado donde la clave es entender las conexiones entre las diferentes semióticas que actúan en el mundo sin dar preferencia a la lingüística (Watson 2009).

En cuanto a la cuestión de la "agencia", los hermenéuticos, los numerosos individualistas metodológicos y los cognitivistas (e.g. DeMarrais et al. 2004) insisten de formas distintas en que los fenó- menos sociales son fundamentalmente explicables partiendo del individuo, negando así la emergencia por encima del nivel del sujeto. La teoría de la complejidad permite a Deleuze entender la individualidad como un subproducto emergente involucrado siempre en distintos procesos de construcción, un conjunto de pliegues del mundo exterior que producen una interrelación única en cada caso (ver Deleuze 1989). El sujeto no emerge con la comunicación (constructivismo), ni en la intersubjetividad (funcionalismo), sino en la intersección de líneas de fuerza y poder que actúan directamente sobre los cuerpos, segmentándolos y ordenándolos (Bogard 1998). Así, la identidad se configura mediante la adopción y proyección al exterior de los espacios en los que se mueve el individuo, espacios de existencia determinados por cuestiones geográficas que condicionan posibilidades de movilidad, vinculación emocional y relaciones a establecer con otras identidades.

La subjetividad nace como perspectiva, emplazamiento o domicilio desde el que se accede al conocimiento y al mundo, como un lugar particular desde el que se experiencia la realidad. La agencia "emerge como una cuestión de distribución de capacidades de acción dentro de espacios y lugares que no son puntos de origen pre-existentes, sino producto de sus esfuerzos por organizar un espacio limitado. Remite así a instalaciones estratégicas posibilitadas por movilidades estructuradas que definen y habilitan ciertas formas de agencia y no otras para poblaciones particulares" (Briones 2005: 18). Según Grossberg (1996), los individuos dan un sentido al mundo y generan sus significados y vínculos emocionales alrededor de ciertos patrones de movilidad estructurada que define formas de circulación social y geográfica que atribuyen accesos diferenciales a los recursos (capital cultural, económico, etc.). Para su análisis desde un punto de vista arqueológico, estos patrones no han de ser considerados como determinismos económicos o culturales, sino como tipos de vida que ciertas estructuras sociales permiten llevar a los individuos, y dentro de los cuales estos pueden o no acceder a esos recursos. Así, las conductas sociales de los humanos (individuales y colectivas) emergen siempre de forma novedosa alrededor de formas de articulación y/o captura (del jefe tribal, del estado, del mercado) que territorializan/estabilizan ciertas prácticas que cristalizan en ciertas formas de identidad. Actos de desterritorialización abren la puerta del movimiento al cambio, tanto individual y colectivo, abriendo nuevas trayectorias de vida $y$, por lo tanto, nuevas perspectivas de experiencia (subjetividades), vinculaciones identitarias, y posibilidades de actuación (agencia). Se evita así el individualismo metódico 
y la hermenéutica de la agencia como resistencia para entender la posibilidad de actuación y cambio por debajo de las estructuras y por encima del individuo, en los llamados "agenciamientos" o "máquinas sociales".

Así, podemos dejar de categorizar a los individuos -"se es" o bien esto o aquello- y permitir que fluyan las conexiones -esto $y$ eso $y$ también aquello $y . . .-$ (Deleuze 2004: 199) entendidas como distintos grados de intensidad diferencial, que se pueden representar con gradientes o fractales: esto es lo que Yanai (2002) concibe como zonas de indiscernibilidad en su estudio de los mapuches, o Hernando y González Ruibal (2001) como personas fractales en su original investigación de los Awá-Guajá. En ambos casos el diagrama del "espacio fase" de ambas comunidades se encuentra en el "umbral" entre el atractor de la modernidad, y el atractor de la tradición, lo que provoca cambios en sus formas de autoorganización y una gran divergencia en las filiaciones identitarias de cada individuo, que no puede caracterizarse como "o bien Mapuche o bien Huinca" o "bien Awa, o bien Brasileño": ambas identidades no se oponen sino que se contagian recíprocamente de modo que los individuos se encuentran en un proceso de cambio constante: "Mapuche y Católico y Chileno y..." La apertura de nuevas trayectorias de vida determina qué lugares pueden ocupar los individuos, cómo los ocupan y qué nuevos patrones de movilidad estructurada tienen que les abren la puerta a nuevas agencias y subjetividades que transforman forzosamente las filiaciones identitarias, en un proceso no-lineal de cambio.

Donde Ruibal y Hernando, a partir de Žižek, consideran el "espectro de lo Real" lacaniano como un indecible (Hernando y González Ruibal 2001: 36), una otredad o ausencia de algo -la mencionada carencia como concepto fundamental del psicoanálisis- (Rajchman 1998) que permite mantener la homeostasis (suplir carencias para re-establecer el equilibrio) del grupo, Deleuze postularía un exceso de nuevos deseos, un proceso de interferencia recíproca donde lo Awá-Guajá y la multiplicidad de lo moderno brasileño existen realmente como potencialidades virtuales dentro de la gradiente de opciones de cambios y estabilizaciones que se les ofrecen, o "estado fase" en términos de la complejidad (sobre el debate en torno al concepto de ideología entre Deleuze y Žižek, ver Sinnerbrink 2006). En consecuencia, y a causa de la emergencia de nuevas relaciones externas a sus propiedades internas como grupo, los Awá-Guajá desarrollan nuevas capacidades y establecen constantemente equilibrios inestables originales donde negociar el cambio sin perder su balance interno. Así, pueden devenir o convertirse en Awá-Guajá-trabajador de FUNAC-vestido; moderno-desnudo-Awá-Guajá, etc. Sea como fuere, estas sociedades se encuentran en un momento de cambio muy sensible a variaciones mínimas iniciales que pueden conllevar transformaciones ingentes a largo plazo, incluyendo la fragmentación de los grupos si los atractores -modernos, tradicionales y toda la gradiente entre ambos extremos- se alejan demasiado física o molarmente o aumentan en intensidad a nivel molecular. En el caso de los Awá-Guajá, vestirse o no vestirse puede convertirse en una singularidad que represente el límite entre el atractor de la modernidad y el de la tradición. Especialmente en un momento de inestabilidad, que un miembro respetado de la tribu decida vestirse puede conllevar una bifurcación en todo el sistema y generar un nuevo atractor de comportamiento. Contextos de cambio como estos deberían ayudarnos a pensar, sin recurrir a la analogía directa, transformaciones que en arqueología se explican de forma categórica y estática como la romanización (ver Marín Suárez y González Álvarez 2011). ¿Qué nuevas trayectorias de vida abrió la conquista a los pueblos indígenas del Noroeste peninsular? ¿De qué formas se hibridaron las subjetividades e identidades locales con las foráneas dentro de las nuevas distribuciones de agencia y movilidad establecidas?

En resumen, Deleuze ofrece una vía de escape al problema estructura/agencia al no considerar la "estructura" como una entidad estática o como parte del mundo del lenguaje, ni la "agencia" como una excepción concedida a los seres humanos que desafía las leyes de la naturaleza y los condicionantes de la estructura (Bonta y Protevi 2004: 6). También se flanquea la dicotomía estructura/proceso: los individuos (bien sean estructuras, sistemas o agentes humanos) son a la vez proceso $y$ resultado. No se trata tan solo entonces de oponer individuo/sociedad: la subjetividad se encuentra a distintos niveles entre ambos. Los individuos se pliegan y despliegan fractalmente, interiorizando, dejando pasar o transformando distintas conexiones y flujos (Deleuze 1989); una tesis ya avanzada hace más de un siglo por el sociólogo Tarde, quien, contra Durkheim, mantenía que tanto el individuo como la sociedad no son más que cristalizaciones momentáneas de la multiplicidad de fuerzas producto de una "cooperación creativa" entre cerebros y cuerpos (Lazzarato 2002).

\section{Multisubjetividad, interferencia recíproca}

Continuando nuestra crítica externa de la arqueología, cabe añadir que desde una visión deleuziana lo que se fomenta es la multisubjetividad: la prolife- 
ración de subjetividades arqueológicas informadas y no de las imposibles cientificidades positivistas, multivocalidades o simetrías epistemológicas. Así, lo interesante del estructuralismo de Criado (1991), la dialéctica psicoanalítica de Ruibal (GonzálezRuibal 2010) o del pragmatismo de Francovich (ver Alonso González y Aparicio Martínez 2011) no es en cuánto sus proyectos/discursos se acercan a la verdad (presente o pasada), sino cuánta relevancia tienen para cuántas personas, qué subjetividades generan entre el público y entre los arqueólogos y qué elementos agencian para sus arqueologías (SIG, etnografía, subvenciones, método Harris, vinculaciones políticas, etc.). Así, "pensar científicamente no es ni corresponder lo visto con lo dicho, ni ordenar y sistematizar lo concebido sino problematizar, esto es, vincular un conjunto de singularidades a través de sus diferencias" (Gallego 2011).

Esto no les excluye, ni a ellos ni a los criterios de demarcación que les juzgan, de estar inmersos en relaciones de poder. Pero el punto es que la verdad no se puede oponer directamente al valor: en realidad es el valor quien sustenta la creación de verdades arqueológicas, no como esencias sino como atractores capaces de agenciar más y más individuos en su apoyo, como ha demostrado Latour en sus estudios sobre la construcción de verdades científicas (Latour y Woolgar 1986). Cuando nuevas voluntades no tienen cabida dentro de los atractores existentes (e.g. revistas ISI positivistas), aquellas se amalgaman en torno a nuevos atractores (estudios post-coloniales, género, teoría, etc.) que capturan estos nuevos flujos de deseo en transformación constante.

Aquí flanqueamos la falsa oposición establecida por Witmore (2007: 305), en relación a la eclosión de un hiperpluralismo de puntos de vista en arqueología, entre la posición de Hodder (2000) - más puntos de vista son bienvenidos: pluralismo-y Olsen, Shanks y Witmore (2003) -la fragmentación impide la crítica. En realidad en ambas visiones subyace en potencia la idea de "poder dominar" o realizar una síntesis global de todas las corrientes arqueológicas; ambos expresan un juicio trascendental en el que se otorgan el derecho a pensar el "cómo debería ser": pluralismo o fragmentación. En lugar de este juicio transcendental, más vale asumir la heterogeneidad de las múltiples perspectivas sobre lo real de forma inmanente y evitar la nostalgia por aquellos tiempos donde había sólo dos posturas teóricas enfrentadas - procesualismo vs. posprocesualismo, ¿existe algo más hegeliano-dialéctico?-que permitían definir posiciones e intercambiar golpes entre estrellas mediáticas de departamentos de arqueología anglo-noroccidentales.
Seguidamente, Witmore asegura que "esta fragmentación ha dejado a la arqueología en una posición tal que la obliga a luchar bajo la bandera de otras disciplinas y ciencias, frente a lo que sería una forma de pensamiento puramente arqueológico" (Witmore 2007: 305). Una paradoja ya que la arqueología simétrica importa directamente de la Teoría-Actor-Red todas sus categorías. El análisis de la relación ciencia-filosofía en Deleuze sobrepasa nuestra intención aquí (ver Gallego 2011; May 2005). Sin embargo, a partir de la investigación del físico cuántico deleuziano Holdsworth (2006), podemos ver cómo tanto la matemática como la teoría literaria llevan a cabo prácticas intelectuales y teóricas similares e interconectadas: los criterios de validación no han de ser exclusivamente internos a la disciplina y por ello es saludable una interferencia recíproca. Nuestra posición aboga por un diálogo directo con la filosofía, práctica habitual en otras disciplinas de las que indirectamente importamos modelos y filosofías deformadas, con consecuencias embarazosas (Olsen 2007). De hecho, los autores más citados fuera del mundo arqueológico son los que han emprendido un diálogo directo con la filosofía (i.e. Tilley o Hodder). También resultan dudosos los postulados en contra de la importación de modelos alógenos (e.g. Webmoor 2008; Witmore 2005) por otra razón: afirman implícitamente que existe un alma mater disciplinar de la arqueología, cuando ésta en realidad es el producto de un proceso emergente de dos siglos cuyo atractor es tan estable que se encuentra oculto: como bien señala Viveiros (2007: 101) para la antropología, esta no tiene nada de original, habiendo importado/asumido como fundación una filosofía bimilenaria helenística y un modelo científico que parte de Descartes. En realidad, los núcleos duros de las ciencias sociales están tendiendo a difuminarse y reconfigurarse en torno a "cuestiones de interés" - matters of concern- como el "patrimonio" o el "cambio climático", que requieren precisamente de intercambio y flexibilidad, y no de la rigidez disciplinar arqueológica y su búsqueda de "hechos de la realidad" - matters of fact (Latour 2004: 104).

\section{Complejidad}

Pese a que la filosofía deleuziana concuerda con las ciencias modernas y con la TC (Hardt 1993) la relación entre ambas ha permanecido largamente inexplorada por la negativa de los científicos a adentrarse en su jerga, y la alergia de muchos científicos sociales al diálogo con las ciencias puras (DeLanda et al. 2005). En general, la TC permite pensar y analizar las capacidades de auto-organización y emergencia 
propias de un sistema de forma inmanente, es decir, sin necesidad de interferencias externas, por lo que resulta útil de cara a una arqueología crítica.

En primer lugar, TC no equivale a teoría del caos: la primera trata la emergencia de estructuras simples a partir de intercambios complejos entre las partes de un sistema, mientras la segunda analiza el desarrollo de comportamientos impredecibles a partir de reglas sencillas en sistemas dinámicos. Una va de lo complejo a lo sencillo, la otra de lo sencillo a lo complejo (Protevi 2006: 4). En segundo lugar, no hay una TC. Law (2004) y Kwa (2002) han intentado condensarlas en dos extremos (Fig. 1):

- Teorías románticas, propias de la cibernética y la computación, caracterizadas por visiones holísticas del mundo, donde leyes naturales estáticas permiten dar cuenta de las entidades del mundo (Hillier 2007: 45). Son las que se aplican en cálculos complejos en arqueología a través de programas como los SIG.

- Teorías barrocas, donde no existe una distinción entre los individuos y sus entornos, enfatizando la continuidad y falta de coherencia de las relaciones entre entidades. Aquí es donde encajaría Deleuze.

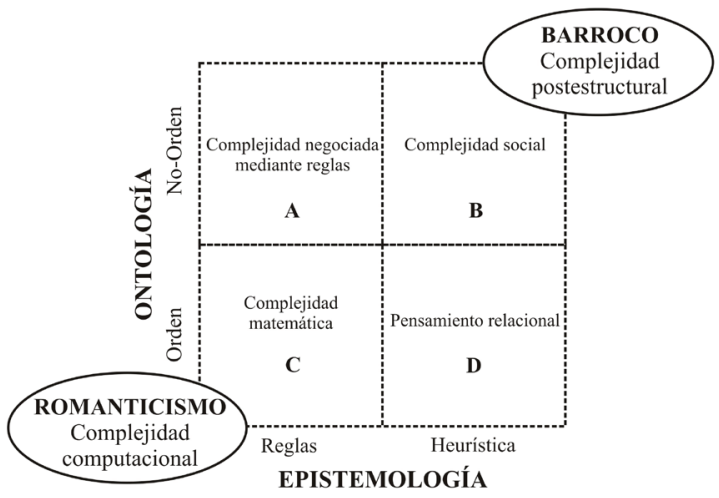

Figura 1.- El paisaje de la complejidad. Adaptado de Snowden y Stanbridge (2004: 144).

El pensamiento complejo es tanto una forma de pensar la realidad como de generar modelos para analizarla. Estos modelos se adaptan a la complejidad del problema que afrontan. Modelos más simples permiten una mayor generación de conocimiento en el sentido "oficial/positivista" del término: aportan una mayor capacidad de predecir cambios. Pero "si construyendo un modelo se asumen demasiadas simplificaciones ... el resultado es un conocimiento ilusorio" (Bonta y Protevi 2004: 17). La clave es encontrar un balance entre simplificación y complejidad. Esto es más sencillo en modelos lineares, caracterizados por su homogeneidad interna, ausencia de agresiones externas y un equilibrio termodinámico general. Sin embargo, en la mayor parte de sociedades durante la historia prevalecen las dinámicas no-lineares y la falta de equilibrio (Ibíd.: 18). Estos sistemas "alejados del equilibrio" pueden caracterizarse por la ausencia de patrones estables de comportamiento o por su existencia, en cuyo caso se habla de sistemas con capacidad de "auto-organización" (Silberstein y McGeever 1999).

Los sistemas sociales permanecen normalmente estables gracias a los mecanismos de retroalimentación. Estos permiten al sistema recuperarse de sus inevitables fluctuaciones/perturbaciones, que pueden generarse de forma endógena o tratarse de respuestas a eventos externos (violencia, intercambio comercial, cambios climáticos, variaciones en el curso de ríos e intensidad de las crecidas en cursos como el Nilo, Tigris o Éufrates, etc.). Estos cambios externos que afectan al sistema se denominan "disparadores" o "signos" (e.g. llevar una tribu a una reserva "dispara" nuevas formas de organización). Deleuze escapa al posmodernismo al concebir los signos más allá del lenguaje; siendo el significado la probabilidad de disparar una respuesta en un sistema determinado (Varela 1991: 96).

Cuando las fluctuaciones alcanzan una cierta magnitud, superando la capacidad de recuperación del mecanismo de retroalimentación, el sistema pasa un umbral del que ya no se puede volver atrás. Posteriormente, el sistema puede:

\section{Descomponerse y pasar a ser caótico.}

2. Resistir el "disparador" externo que altera el sistema y volver a equilibrarse en un patrón similar previo: "desterritorialización relativa", según Deleuze.

3. Estabilizarse en torno a nuevos atractores, es decir, nuevos comportamientos: el sistema puede "aprender" (Protevi 2006: 6): "desterritorialización absoluta". Aquí podríamos debatir sobre cuestiones identitarias que sólo planteamos: ¿ante una desterritorialización absoluta ha desaparecido el sistema anterior y nos encontramos con una nueva identidad? ¿O se trata de una identidad transformada? ¿Qué queda de la identidad 'maya' tras la conquista española o de la de los indígenas peninsulares tras la conquista por Roma?

Los Awá-Guajá y los Mapuches, como agenciamientos sociales, poseen resistencia y elasticidad, siendo la reacción habitual la de volver a patrones de comportamiento previos. Si bien pueden "aprender", no pueden "olvidar", y la aparición del atractor de la modernidad no puede desapa- 
recer sin más. Lo que llamamos "aprendizaje" puede equipararse habitualmente a otros sistemas parecidos -"desarrollo"-, pero otras veces se trata de una creación pura -"evolución"-, donde se generan patrones completamente originales dentro de un sistema. Esto es lo que Deleuze denomina "evento", que daría lugar a una "totalidad emergente" novedosa. En el caso de sistemas sociales, aquí podríamos situar el cambio social y la "agencia". Como vemos, esta no tiene por qué encontrarse en un solo individuo o en una estructura, sino que es normalmente co-producida por nuevas redes de relaciones en interferencia recíproca. La emergencia puede ser sincrónica (un conjunto de ciudades-estado que se unen para formar una alianza) o diacrónica (una nueva forma de territorializar y codificar el espacio, como el feudalismo).

En la filosofía deleuziana, el ámbito de lo "virtual" refiere precisamente a estos patrones, umbrales, atractores y singularidades que se encuentran detrás de los procesos de morfogénesis - de generación de realidad material-, que conforman las realidades materiales y comportamientos de nuestra experiencia cotidiana, el ámbito de lo "actual". Como vemos, la causalidad que se imbuye a los sistemas no es final (nos llevaría a explicaciones teleológicas y transcendentales) ni eficiente (nos llevaría al determinismo positivista y a la imposibilidad de explicar la causa original), sino que simplemente lo virtual funciona como una "casi-causa" de los procesos actuales (DeLanda 2004: 78-80). Como ejemplo abstracto podría servir el entender la "autoridad central" como "casi-causa" que evita la aparición de la desigualdad en las comunidades de cazadoresrecolectores y algunas comunidades campesinas (pasadas y presentes). Estos grupos poseían mecanismos para disipar el prestigio y evitar el establecimiento de jefaturas permanentes, y para eliminar o redistribuir los excedentes que pudiesen dar lugar a la acumulación de reservas (e.g. el Potlatch). Pese a que las jefaturas y la acumulación de excedentes no se lleguen a actualizar o materializar nunca en estos grupos, aquellas tienen un estatuto ontológico real a la vez que virtual según Deleuze. La posibilidad de una autoridad central no es entonces una eventualidad no realizada, sino una virtualidad que dispara procesos materiales en la realidad de la comunidad, que instituye prácticas para evitarla. Es decir, no se trata de posibilidades no reales, sino de atractores en potencia en el diagrama del espacio fase (momento socio-biológico que la comunidad atraviesa) que tienen "agencia" sobre la realidad. Y precisamente poseen "agencia" porque no se han actualizado, es decir, provocan ciertos comportamientos diferentes a los que provocarían si se actualizasen: funcionan como casi-causas.
Ahora estamos en una mejor posición para entender la idea deleuziana de individuo y la constitución de su identidad. Para él, el problema con la "diferencia" es que siempre se había conformado en relación a una identidad primera: diferencia de $\mathrm{X}$, o entre U y C. Con esta lógica, la identidad se convierte de nuevo en la base de la ontología, y lo pre-individual se caracteriza por una diferencia negativa (Hegel). Esta es la forma característica de la mirada colonial, expandida durante la modernidad. Según Grossberg (1996), que las identidades se construyan por diferencia es un "legado típico de una modernidad que siempre se ha construido a sí misma diferenciándose de otro -como 'tradición' en sentido temporal, o como 'los primitivos'/'los étnicos' en tanto otros espaciales transformados en otros temporales- en un juego que confina a los/sus 'otros' a responder por inversión" (cit. en Briones, 2005: 18). Para Deleuze, la alteridad no tiene por qué concebirse en términos dialécticos -lo "Otro" como refuerzo de mi propia identidad-, sino como un proceso constante de transformación por imitación, variación, diferenciación... Conocer pasa a ser sinónimo de construir o dialogar: construir realidad, construir subjetividad, y deja de ser una tarea del sujeto que conoce, reflexiona, $o b-$ serva, comunica o representa (Deleuze y Guattari 1999). La capacidad de actuación o "agencia" se encuentra así dispersa entre distintos agenciamientos, sujetos a su vez a distintos atractores, y no en el individuo cartesiano racional y autosuficiente o en el determinismo de ciertas estructuras. Así por ejemplo, los estudios etnoarqueológicos de comunidades vernáculas españolas (González Ruibal 2003; González Alvarez 2007; Alonso González 2009), muestran cómo estas se hayan atrapadas entre distintos atractores virtuales que las hacen tender hacia la modernidad, la tradición y la posmodernidad, y que convergen en una misma dimensión espacio-temporal encajada a la vez dentro de agenciamientos múltiples (la Iglesia, la cultura de la posesión de la tierra, la llegada de los aparatos del estado del bienestar y del consumismo post-industrial, entre otros). La originalidad de estas formaciones sociales y las trayectorias vitales que se les abren a sus individuos impiden que las podamos clasificar por analogías, diferencias o similitudes, o comparar con otras. Pese a que los aspectos molares, la fisonomía de los pueblos y la dedicación de sus habitantes a ciertas tareas puedan parecer similares a otros, sus aspectos moleculares serán siempre variables al estar implicados en distintos atractores: ninguna sociedad o individuo cambia hacia algo a la vez que arrastra consigo un mismo tipo de energías, hábitos, deseos y emociones. 


\section{Pensar lo social, agenciamientos}

Pensar lo social es fundamental en las explicaciones/ interpretaciones arqueológicas: todas ellas derivan implícitamente de una teoría o modelo de pensamiento social. El modelo aplicado "por defecto" sería el del sentido común contemporáneo, pero este nos llevaría al presentismo, i.e., la proyección hacia el pasado de valores actuales (Stocking 1965; Moro en este volumen). Por ello, se considera necesaria la introducción de variables que sirvan de mediadoras epistemológicas (teorías, modelos) entre la realidad estudiada y el investigador. Esto es, se trata de crear la ficción de un sujeto investigador que se abstrae de su contexto para ser "objetivo". Dejando de lado la discusión de esta cuestión, es fundamental tener en cuenta que toda investigación arqueológica aplica un modelo concreto que determina las realidades y entes que pueblan lo social (ontología). Como hemos visto, la ontología plana deleuziana en su explicación de lo social no prioriza ni al individuo ni a la estructura, concibiendo lo social como un continuum cambiante poblado por agenciamientos que modulan la realidad.

El concepto de agenciamiento nos permite pasar del ámbito de lo ontológico a lo social, aunque en principio los agenciamientos no son exclusivamente sociales: pueden ser financieros, políticos, ecológicos, etc. El término fue adoptado de Foucault por Deleuze (1988b) con el objetivo de superar los determinismos sociales marxistas, fenomenológicos y estructuralistas, y dar cuenta de procesos de emergencia de nuevas configuraciones a través de la determinación recíproca.

Un agenciamiento está compuesto por elementos dispares conectados por relaciones transversales en un sistema donde predomina la causalidad no-linear (Zaera-Polo 2008: 90). En la Teoría-Actor-Red el agenciamiento sería un descriptor "de estructuras heterogéneas compuestas de elementos humanos y no-humanos" (Palmås 2007: 2). Conectando con la exposición previa, los agenciamientos pueden ser equiparables a "totalidades emergentes", variables dependientes del ejercicio de las capacidades de sus partes relacionalmente (Deleuze y Guattari 2004 \#1158). Un agenciamiento es siempre un producto histórico fortuito que ha reunido sus componentes de un modo particular: no pertenecen a categorías sino que son únicos, individuales. Pese a ello, hay muchos agenciamientos similares porque los atractores y singularidades que pueblan el mundo son mayoritariamente parecidos (DeLanda 2011: 186). Pensar la explicación/interpretación arqueológica mediante agenciamientos nos permite dar cuenta de estructuras productoras de subjetividades en constante transformación, ayudándonos a pensar de una forma no determinista para deshacernos de las herencias histórico-culturales: no pensar en fases (ni cronológicas ni de modos de producción), ni por analogías (como las establecidas por la etnoarqueología procesualista deconstruida por González Ruibal (2003) o basándonos en la búsqueda de grupos étnicos esencializados (los astures, los cántabros, etc.).

La primera división en los roles que cada componente desempeña en el agenciamiento es entre "materia" y "expresión". Los aspectos materiales incluyen los cuerpos y cerebros humanos como base de la interacción social, herramientas tecnológicas, recursos naturales, arquitecturas y estructuras físicas... Los aspectos expresivos pueden ser lenguajes, símbolos culturales, gestualidad, leyes, comportamientos... Como es habitual en Deleuze, aunque ambos parezcan extremos dicotómicamente separados en realidad siempre se encuentran unidos e interrelacionados a través de la presuposición recíproca. Un buen ejemplo es la diferenciación de las funciones realizadas por el nacionalismo a la hora de construir la nación: así, se pueden desterritorializar ciertos materiales para convertirlos en expresión de una "comunidad imaginada" (Anderson 2006) que a la vez se construye materialmente a partir de estas expresiones, por ejemplo el flamenco, toros, paella o sol/playa en España.

La materia y la expresión no son elementos caóticos esperando a recibir una forma, cada aspecto tiene sus propias "sustancia" y "forma", hay una formamaterial, sustancia-material, y una forma-expresión, sustancia-expresión. Este movimiento deleuziano deriva de la lingüística de Hjemslev en oposición a la de Saussure (Fig. 2), para evitar reducir el agenciamiento al determinismo marxista: la materia/eco-

Semiótica de Saussure

Semiótica de Hjemslev

\begin{tabular}{|c|c|c|c|c|}
\hline \multirow{3}{*}{ Significad } & \multirow{3}{*}{$\begin{array}{l}\text { CONTENIDO } \\
\text { EXPRESIÓN }\end{array}$} & \multirow{3}{*}{$\begin{array}{l}\text { Materia } \\
\text { informe }\end{array}$} & FORMA & SUSTANCIA \\
\hline & & & & \\
\hline & & & & \\
\hline
\end{tabular}

Figura 2.- Diferencias entre las semióticas de Saussure y Hjemslev (elaboración propia). 


\begin{tabular}{|c|c|c|}
\hline & Forma & Sustancia \\
\hline $\begin{array}{l}\text { Contenido } \\
\text { No discursivo } \\
\text { Visible } \\
\text { Material } \\
\text { Territorializable }\end{array}$ & $\begin{array}{l}\text { - Arquitectura de la prisión } \\
\text { - Principio del Panopticón de Jeremy } \\
\text { Bentham. } \\
\text { - Distribución de la luz y la oscuridad. } \\
\text { - Práctica de la regimentación espacial }\end{array}$ & $\begin{array}{l}\text { - Los cuerpos de los prisioneros individuales } \\
\text { con sus propiedades y capacidades } \\
\text { - El material físico requerido para la prisión }\end{array}$ \\
\hline $\begin{array}{l}\text { Expresión } \\
\text { Discursivo } \\
\text { Decible } \\
\text { Inmaterial } \\
\text { Codificable }\end{array}$ & $\begin{array}{l}\text { - Ley penal } \\
\text { - Enunciaciones en relación a la } \\
\text { delincuencia } \\
\text { - Los antecedentes penales } \\
\text { - La organización de los argumentos } \\
\text { jurídicos }\end{array}$ & $\begin{array}{l}\text { - Los elementos discursivos (sujetos y } \\
\text { objetos) producidos por las definiciones de } \\
\text { delincuencia y criminalidad }\end{array}$ \\
\hline
\end{tabular}

Figura 3.- Análisis del surgimiento de la prisión según Michel Foucault, a partir de Deleuze (1988b).

nomía condiciona la expresión/cultura (superestructura); o al estructuralismo/hermenéutica/antropología cultural (e.g. Geertz 1973): la expresión condiciona la materia, o bien la reduce al modelo significante/ significado.

La expresión y la materia se presuponen recíprocamente, hay interferencias no-lineares entre ambos. La expresión pasa a estar dentro del mundo con efectos a su alrededor, no simplemente representando al mundo o transmitiendo información (Srnicek 2007). Deleuze consideraba el estudio del sistema de prisiones realizado por Foucault un buen ejemplo de este tipo de análisis, que podría extenderse fácilmente a contextos de explicación/interpretación arqueológica (Fig. 3).

Dos procesos dan dinamismo a los agenciamientos y dan cuenta de su grado de homogeneidad y consistencia y de cómo han llegado a conformarse o disolverse:

1. Procesos que actúan sobre los elementos físicos, sobre la materia: territorialización/desterritorialización. Un agenciamiento con componentes similares tendrá una identidad más definida/territorializada que uno con elementos más heterogéneos. Unas fronteras bien definidas o difusas y fluctuantes también denotan distintos grados de intensidad identitaria (DeLanda 2011: 187). Frontera puede referirse a la capa exterior de un electrón, el límite de un ecosistema o captación de recursos de una comunidad, o una nación. Procesos de territorialización estabilizan fronteras y consistencias de agenciamientos a corto y largo plazo: cazadoresrecolectores se territorializan en comunidades campesinas, son desterritorializadas por nómadas, etc. También se pueden territorializar barrios para homogeneizarlos (gentrificación), etnias (holocausto judío), clases (purgas de blancos en la URSS) o razas (apartheid). A través de la territorialización un sistema material se organiza alrededor de un atractor particular (Srnicek 2007). Por su parte, la desterritorialización de un sistema puede ser relativa (vuelta a un patrón similar - movimiento social conservador) o absoluta (apertura del sistema a nuevos atractores y al cambio - movimiento social aperturista). Ambos procesos generan subproductos:

- La territorialización suele producir entidades molares: instituciones, centros de organización y autoridad, jefaturas, familias..., que capturan los flujos de energía y relaciones externas entre elementos para centralizarlas y garantizarse su reproducción.

- Las desterritorializaciones facilitan la desestructuración de espacios estriados y estructuras molares, al descomponer agenciamientos materiales previamente estables y liberar la trayectoria de partes distintas hacia nuevos atractores. Estos son momentos de crisis y transformación social hasta que un nuevo patrón dominante vuelve a establecerse y tratar de recapturar los flujos liberados. Como bien muestra Sassen (2006), estas transformaciones no son prácticamente nunca totales, y ciertos atractores pueden mantenerse latentes y reaparecer posteriormente. Según él, esto sucedió en el caso de los agenciamientos medievales que resultaron fundamentales en la construcción del estado-nación, algo que se escapa a miradas hacia el pasado que tienden a plantearlo en términos de fases y/o estructuras en lugar de agenciamientos. 
2. Procesos que actúan sobre los elementos simbólicos o la expresión: codificación/descodificación. Estos sirven para dar consistencia, o quitársela, a una formación social o individuo en su expresión, que pueden tener efectos indirectos en la organización de lo material. Un agenciamiento está más codificado cuanto más sus mecanismos de emergencia están determinados por ciertos parámetros. Por ejemplo, el comportamiento social está más codificado en una ciudad-estado griega que en una tribu nómada; el desarrollo de algunos seres está más determinado por sus genes que el de otros. Igualmente, las comunidades paleolíticas se sirvieron del lenguaje para codificar los elementos fundamentales para su convivencia: lo sagrado, lo tabú, lo ordinario... (DeLanda 2011: 186).

Territorialización y codificación no tienen por qué producirse a la vez. Por ejemplo, las tribus bárbaras desterritorializaron el Imperio Romano, reterritorializándolo con unas nuevas fronteras y desequilibrando la consistencia y relaciones internas de los territorios (entre ciudades, clases, etnias, etc.). Sin embargo, estas mismas tribus venían ya siendo y fueron mayoritariamente re-codificadas parcialmente por el lenguaje, la jurisprudencia y la cultura latina.

Dos apuntes finales completan esta esquemática caracterización del agenciamiento:

1. Cada agenciamiento debe ser tratado como una entidad histórica única caracterizada por una serie de propiedades emergentes que fluctúan cerca de un atractor, cuyos cambios son contingentes y producto de una historia no linear y no teleológica (DeLanda 2000). Lampert (2006) ofrece varias razones para afirmar la contingencia de la historia:

a) Los eventos son intersecciones de encuentros independientes, que podrían haber ocurrido antes, diversamente, o no haber ocurrido.

b) Los eventos se dan caóticamente y sin condiciones predeterminadas.

c) Distintos eventos acontecen a ritmos y temporalidades diversas y por lo tanto no existe una causalidad eficiente de las unas sobre las otras.

d) Los eventos dependen de condiciones del entorno, que a su vez dependen de otras condiciones, hasta el infinito (contra b).

e) Los eventos derivan de actividades minoritarias, no de causalidades a gran escala.

f) Los eventos son irreducibles, indeterminados o ambiguos, siendo imposible determinar totalmente sus factores determinantes.

Esta necesidad de considerar siempre las entidades del pasado que analizamos como únicas es lo que lleva a Deleuze a flanquear también la dicotomía inducción/deducción. Abraza así la abducción, también llamada retroducción, forma de razonamiento desarrollada por Peirce (1935) que asume la importancia que la intuición del científico o pensador tiene como única forma de desarrollar hipótesis novedosas (Martín Gallego 2011).

2. Cada agenciamiento se caracteriza por la estructura de espacios potenciales que definen sus capacidades y trayectorias, es decir por un diagrama o "espacio fase". A falta de leyes o determinismos gobernando el devenir histórico, sólo nos queda cartografiar su potencial de evolución y las fluctuaciones que, superando un determinado umbral, pueden transformar radicalmente el sistema (de una comunidad, un estado, una tribu). Así, la tendencia a crear categorías estáticas se sustituye por procesos de los que hay que dar cuenta: no hablamos de "categorías" sino de entidades estabilizadas por procesos de territorialización y codificación realizados por atractores poderosos, pero no concebidos como leyes eternas, estáticas o inmutables, como ocurre en el procesualismo.

Pensar a través de agenciamientos nos permite concebir lo social en arqueología en términos dinámicos, evitando los determinismos del funcionalismo (de Parsons a Bourdieu), los determinismos lingüísticos o de clase (hermenéutica, estructuralismo, marxismo) y los individualismos y racionalismos, además de las divisiones dentro de la sociedad en sectores (como en Luhmann, entre lo legal, lo político y lo económico). Permite también matizar la omnipresencia de "relaciones de poder" en los análisis del primer Foucault.

\section{Conclusión}

Esta reflexión ha de considerarse como una caja de herramientas para arqueólogos y antropólogos que pretendan desarrollar nuevas estrategias de pensamiento e investigación dejando de lado la dicotomía procesualismo/posprocesualismo sin por ello retrotraerse al "buen trabajo de campo" o a la tradición histórico-cultural. No se ha tratado específicamente la cuestión política porque Deleuze no la considera un ámbito distinto de la ciencia o el arte. La política es co-constitutiva de la realidad, es decir, directamente ontológica antes que epistemológica: toda decisión de investigación es inmediatamente política y viceversa. Igualmente, la disciplina arqueológica es directamente productora de realidades, que construye agenciándose con distintos discursos, materias, sistemas e instituciones, creando sus propios valores y verdades. Estos no son "relativos" u "objetivos/subjetivos", sino que son simplemente inmanentes a cada forma de pensar y practicar la arqueología, que incluso en sus variables proce- 
sualistas más radicales produce siempre distintas realidades e interpretaciones, al no poder recrear sus condiciones de investigación de forma aislada en un laboratorio.

¿Para qué sirve una arqueología con una epistemología simétrica? Para intentar esconder las desigualdades de poder derivadas de domicilios de investigación privilegiados desde los que se produce el discurso arqueológico y demostrar (a nosotros mismos, a la sociedad y a las instituciones) la aparente justicia y equidad de nuestra tarea como investigadores (y, de paso, acumular capital cultural/ académico). Desde una óptica deleuziana, nuestras formas de conocer la realidad (epistemología) están directamente vinculadas a cuestiones políticas en relación a qué y cómo se construye la realidad y el conocimiento que la habita (ontología). Esta construcción debería ser nuestra preocupación esencial como individuos y profesionales: ¿qué agenciamientos sociales, políticos, económicos e institucionales favorece mi trabajo/investigación? ¿Qué cambia en el mundo después de haberla concluido y divulgado? ¿Qué produzco, a quién afecto y cómo soy afectado al excavar una fosa común de la Guerra Civil?

La filosofía de Deleuze sirve para establecer un lenguaje y una forma de razonar común con las TC que facilita la recepción crítica y adopción de desarrollos en las ciencias duras como la neurociencia social. Gracias a la superación de pensamientos dialécticos, tipológicos y estáticos, nos permite abrazar una visión dinámica de la realidad y sus variaciones. Deleuze nos aleja de binarismos de herencia hegeliano-marxista que subyacen al discurso arqueológico: individuo-sociedad, sujeto-objeto o estructura-proceso. La dialéctica siempre resuelve y cosifica estos binarismos a favor del componente hegemónico: identidad sobre diferencia, universalidad sobre la multiplicidad del sentido... Igualmente, el "yo y el otro" se sintetizan en la "intersubjetividad" o "reflexividad", "sujeto y objeto" en la "comunidad", "individuo y sociedad" en "Sociedad" como representación colectiva, etc. Para Deleuze, estas soluciones simplemente desvían la atención del verdadero problema de la multiplicidad y su complejidad: todos los seres son múltiples, poseen verdaderas composiciones diferentes que no pueden reducirse a la lógica del "X" o "no-X". La arqueología debe intentar aprehender esta complejidad sin miedo a perder potencial explicativo. La cuestión fundamental no es buscar analogías entre el registro y meta-narrativas explicativas, o entre arqueología, Deleuze y Teoría de la Complejidad en nuestro caso, sino intentar pensar la diferencia y en modos diferentes sobre el pasado desde el presente.

\section{Notas}

1. Este artículo se encuadra dentro de los proyectos de investigación HAR2010-21950-C03 "La formación de los paisajes del NO peninsular durante la Edad Media (Siglos V-XII)", Ministerio de Ciencia e Innovación de España; y LE302A11-1 "León en la Alta Edad Media. El territorio de Cea entre los siglos V-XII”, Junta de Castilla y León (España).

2. El concepto de "multiplicidad" usado en la TC puede equipararse con la imagen deleuziana del "rizoma".

3. Un ejemplo sencillo: al ver una silla asumimos que es un ente sólido y estable, pero sabemos que si permanece así durante mucho tiempo cambiará completamente. Así, damos por hecho el estado molar estable de la silla, pero sabemos que molecularmente no cesan de producirse cambios internos en su composición. Descompuesta, la silla deja de ser "silla" como ente molar, mientras molecularmente seguimos encontrando "lo mismo" (i.e. moléculas) que han sufrido cambios intensivos en su conformación.

\section{REFERENCIAS BibLiográficas}

Alonso González, P. (2009): Etnoarqueología y gestión del patrimonio cultural. Maragatería y Val de San Lorenzo. Junta de Castilla-León, Universidad de León, León.

Alonso González, P.; Aparicio Martínez, P. (2011): Por una Arqueología menor: de la producción de discursos a la producción de subjetividad. Arkeogazte, 1: 21-36.

ANDERSON, B.R. (2006): Imagined communities: Reflections on the origin and spread of nationalism. Verso, Londres.

Bient, J.; Locke, P. (2010): Deleuze and the Anthropology of Becoming. Current Anthropology, 51(3): 317-351.

Bogard, W. (1998): Sense and Segmentarity: Some Markers of a Deleuzian-Guattarian Sociology. Sociological theory, 16(1): 52-74. 
Bonta, M.; Protevi, J. (2004): Deleuze and geophilosophy: A guide and glossary. Edinburgh University Press, Edimburgo.

Bowker, G.C. (2009): A plea for pleats. Deleuzian intersections: science, technology, anthropology (C.B. Jensen y K. Rödje, eds.), Berghahn Books: 123-138.

Briones, C. (2005): Cartografías argentinas: politicas indigenistas y formaciones provinciales de alteridad. GEAPRONA, Buenos Aires.

Brown, S.D. (2009): Deleuze and social science. Deleuzian intersections: science, technology, anthropology (C.B. Jensen y K. Rödje, eds), Berghahn Books: 101-121.

Сномsкy, N., Foucault, M. (1974): Human nature: Justice versus power. Reflexive water: The basic concerns of mankind (F. Elders, ed.), Souvenir Books, Londres: 133-197.

Citton, Y.; Lordon, F. (2008): Spinoza et les sciences sociales. Editions Amsterdam, París.

Criado-Boado, F. (1991): Construcción social del espacio y reconstrucción arqueológica del paisaje. Boletín de antropología americana, (24): 5-29.

DeLanda, M. (2000): A thousand years of nonlinear history. Swerve, Nueva York.

DeLanda, M. (2004): Intensive Science and Virtual Philosophy. Continuum, Londres.

DeLanda, M. (2011): Philosophy and simulation: the emergence of synthetic reason. Continuum, Londres.

DeLanda, M., Protevi, J.; Thanem, T. (2005): Deleuzian Interrogations: A Conversation with Manuel DeLanda, John Protevi and Torkild Thanem. Tamara: Journal of Critical Posmodern Organisational Science, 4(4).

Deleuze, G. (1984): ¿En qué se reconoce el estructuralismo? Historia de la filosofí, Espasa-Calpe, Madrid: 566-599.

Deleuze, G. (1988a): Diferencia y repetición. Júcar, Madrid.

Deleuze, G. (1988b): Foucault. University of Minnesota Press, Minneapolis.

Deleuze, G. (1989): El pliegue. Paidós, Barcelona.

Deleuze, G.; Artal, C. (1971): Nietzsche y la filosofia. Anagrama, Barcelona.

Deleuze, G.; Guattari, F. (1985): El anti Edipo: capitalismo y esquizofrenia. Paidós, Buenos Aires.

Deleuze, G.; Guattari, F. (1999): ¿Qué es la filosofía? Anagrama, Barcelona.

Deleuze, G.; Guattari, F. (2004): Mil mesetas. Pre-textos, Barcelona.

Deleuze, G.; Lapoujade, D. (2006): Two regimes of madness: texts and interviews 1975-1995. Semiotext(e), Nueva York.

DeMarrais, E., Gosden, C.; Renfrew, C. (2004): Rethinking materiality: The engagement of mind with the material world. McDonald Institute of Archaeological Research, Cambridge.

Domínguez Rodrigo, M. (2008): Arqueología neo-procesual: ‘alive and kicking'. Algunas reflexiones desde el Paleolítico. Complutum, 19(1): 195-204.

FAGAN, B.G. (2006): Archaeological fantasies: how pseudoarchaeology misrepresents the past and misleads the public. Routledge, Londres.

FERnÁNDEZ MARTínez, V.M. (2006): Arqueologías críticas: el conflicto entre verdad y valor. Complutum, 17: 191-203.

Fox, N.J.; WARD, K.J. (2008): What are health identities and how may we study them? Sociology of health \& illness, 30(7): 1007-1021.

Gallego, F.M. (2011): Deleuze y la filosofía de la Ciencia. Revista Filosofia UIS, 9(1): 1-19.

Garnsey, E.; McGlade, J. (2006): Complexity and co-evolution: continuity and change in socio-economic systems. Edward Elgar, Cheltenham.

Geertz, C. (1973). Thick description: Toward an interpretive theory of culture. The Interpretation of Cultures. Basic Books, Nueva York: 3-30.

GonzÁlez Alvarez, D. (2007): Aproximación etnoarqueológica a los Vaqueiros d'Alzada: un grupo ganadero transhumante de la montaña asturiana. Arqueoweb: Revista sobre Arqueología en Internet, 8(2).

GonzÁlez Ruibal, A. (2003): Etnoarqueología de la emigración. El fin del mundo pre-industrial en Terra de Montes (Galicia). Diputación Provincial, Pontevedra.

GonzÁlez-Ruibal, A. (2008): Time to destroy. An archaeology of supermodernity. Current Anthropology, 49(2), 247-279.

GonzÁlez-Ruibal, A. (2010): Contra la Pospolítica: Arqueología de la Guerra Civil Española. Revista Chilena de antropología, 22: 9-32. 
Grossberg, L. (1996): Identity and cultural studies: is that all there is? Questions of cultural identity (P. Du Gay y S. Hall, eds.), Sage, Londres: 87-107.

Groves, C. (2009): The Futures of Causality: Hans Jonas and Gilles Deleuze. Causality and Motivation (R. Poli, ed.), Transaction, Frankfurt: 151-170.

Haber, A. (2011): Nometodología Payanesa: Notas de metodología indisciplinada. Revista Chilena de Antropología, 23.

Hamilton, J.A.; Placas, A.J. (2011): Anthropology Becoming...? The 2010 Sociocultural Anthropology Year in Review. American Anthropologist, 113(2): 246-261.

Hardt, M. (1993): Gilles Deleuze: an apprenticeship in philosophy. University of Minnesota Press, Minneapolis.

Hardt, M.; Negri, A. (2000): Empire. Harvard University Press, Cambridge, MA.

Harman, G. (2009): Prince of networks: Bruno Latour and metaphysics. Re-press, Prahran.

Hernando, A. y González Ruibal, A. (2001): Fractalidad, Materialidad y Cultura: Un Estudio Etnoarqueológico de los Awá-Guajá de Maranhão. Revista de Antropología Chilena, 24(2): 9-61.

HiLlier, J. (2007): Stretching beyond the horizon: a multiplanar theory of spatial planning and governance. Ashgate, Aldershot.

Hodder, I. (1982): Symbols in action: ethnoarchaeological studies of material culture: Cambridge University Press, Cambridge.

Hodder, I. (2000): Archaeological theory. Archaeology: The widening debate (B. Cunliffe, W. Davies, y C. Renfrew, eds.), Oxford University Press, Oxford: 77-90.

Holdsworth, D. (2006): Becoming Interdisciplinary: Making Sense of DeLanda's Reading of Deleuze. Paragraph, 29(2): 139-156.

Kristiansen, K. (2008): Should archaeology be in the service of 'popular culture'? A theoretical and political critique of Cornelius Holtorf's vision of archaeology. Antiquity, 82(316): 488-490.

KwA, C. (2002): Romantic and baroque conceptions of complex wholes in the sciences. Complexities: social studies of knowledge practices (J. Law, A. Mol, eds.), Duke University Press, Durham: 23-52.

LAMPERT, J. (2006): Deleuze and Guattari's philosophy of history. Continuum, Londres.

Latour, B., (1984): Les microbes : guerre et paix; suivi de Irréductions. Métailié, París.

Latour, B. (2004): Politics of nature: how to bring the sciences into democracy. Harvard University Press.

LATour, B. (2007): A textbook case revisited: knowledge as mode of existence. The handbook of science and technology studies. MIT, Cambridge: 83-112.

Latour, B.; Woolgar, S. (1986): Laboratory life : the construction of scientific facts. Princeton University Press.

LAW, J. (2004): And if the global were small and noncoherent? Method, complexity, and the baroque. Environment and Planning D, 22(1): 13-26.

Lazzarato, M. (2002): Puissances de l'invention : la psychologie économique de Gabriel Tarde contre l'économie politique. Empêcheurs de penser en rond, París.

Lazzarato, M. (2006): Por una politica menor: Acontecimiento y política en las sociedades de control. Traficantes de Sueños, Madrid.

Lingis, A. (1994): The Society of Dismembered Body Parts. Gilles Deleuze and the Theater of Philosophy (C. Boundas y D. Olkowski, eds.), Routledge, Nueva York: 289-303.

Lordon, F. (2006): L'intérêt souverain: essai d'anthropologie économique spinoziste. Découverte, París.

Lordon, F., Bensaïd, D., Aouillé, S., Bruno, P., Chaumon, F., Lérès, G.; Plon, M. (2010): Capitalisme, désir et servitude. La Fabrique, París.

Mahler, J. (2008): Lived temporalities: exploring duration in Guatemala: empirical and theoretical studies. Transcript Verlag, Bielefeld.

Mahon, M. (1992): Foucault's Nietzschean genealogy: Truth, power, and the subject. State University of New York Press.

Marín SuÁrez, C.; González Álvarez, D. (2011): La romanización del Occidente Cantábrico: de la violencia física a la violencia simbólica. Férvedes, 7: 197-206.

Martin, E. (2010): Self-making and the brain. Subjectivity, 3(4): 366-381.

Martin-Jones, D. (2006): Deleuze, cinema and national identity: narrative time in national contexts. Edinburgh University Press, Edimburgo. 
Martín Gallego, F. (2011): Notas sobre el lugar de la propuesta epistemológica deleuziana. A Parte Rei: revista de filosofía, (75): 4.

Massumi, B. (1992): A user's guide to capitalism and schizophrenia: deviations from Deleuze and Guattari. MIT Press, Cambridge.

Massumi, B. (2002): Parables for the virtual: Movement, affect, sensation. Duke University Press, Durham.

MAY, T. (2005): Gilles Deleuze, difference, and science. Continental philosophy of science (G. Gutting, Ed.), Blackwell, Cornwall: 239-257.

Mora, F. (inédito): Neurociencia. Ponencia dentro del ciclo Neurocultura, Semana de la Ciencia de la Comunidad de Madrid, Círculo de Bellas Artes, 12-11-2007.

Morin, E. (1994): Epistemología de la complejidad. Paidós, Buenos Aires.

Moro, O. (2007): La “arqueología simétrica” o la irrupción de la sociología del conocimiento científico en arqueología. Complutum, 18: 318-319.

Norrie, A.W. (2010): Dialectic and difference: dialectical critical realism and the grounds of justice. Taylor \& Francis.

Olsen, B. (2007): Genealogías de la asimetría: por qué nos hemos olvidado de las cosas. Complutum, 18: $287-291$.

Olsen, B., Shanks, M.; Witmore, C. (2003): Innocence regained? or, Is there a new consensus in archaeology? An alternative case for bold thinking. Archaeology Center Workshop. Stanford University.

Palmås, K. (2007): Deleuze and DeLanda: A new ontology, a new political economy? Paper presented at the Economic Sociology Seminar Series, London School of Economics \& Political Science.

Patton, P. (2000): Deleuze and the Political. Routledge, Londres.

PeIrce, C.S. (1935): Collected Papers of Charles Sanders Peirce: Pragmaticisms and Pragnoaticism, Scientific Metaphysics. Belknapk, Harvard University, Cambridge.

Prigogine, I.; Stengers, I. (1984): Order out of chaos: man's new dialogue with nature. Bantam Books, Toronto.

Protevi, J. (2006): Deleuze, Guattari and emergence. Paragraph, 29(2): 19-39.

Rajchman, J. (1998): Constructions. MIT Press, Cambridge.

Reynoso, C. (2006): Complejidad y caos: una exploración antropológica. Universidad de Buenos Aires, Buenos Aires.

Rosanvallon, J.; Preteseille, B. (2009): Deleuze \& Guattari à vitesse infinie. Ollendorff et Desseins, París.

SASSEN, S. (2006): Territory, authority, rights: from medieval to global assemblages. Cambridge University Press, Cambridge.

Shanks, M. (2007): Arqueología Simétrica. Complutum, 18: 292-295.

Silberstein, M.; McGeever, J. (1999): The search for ontological emergence. The Philosophical Quarterly, 49(195): 201-214.

Sinnerbrink, R. (2006): Nomadology or Ideology? Žižek's Critique of Deleuze. Parrhesia, 1: 62 - 87.

Sмith, L. (2006): Uses of heritage. Routledge, Londres.

Snowden, D.; Stanbridge, P. (2004): The Landscape of Management: Creating the Context for Understanding Social Complexity. Emergence: complexity and organization., 6(1/2): 140-148.

Srnicer, N. (2007): Assemblage Theory, Complexity and Contentious Politics. The political Ontology of Gilles Deleuze. Tesis inédita, University of Western Ontario.

Stengers, I. (2000): The invention of modern science. University Of Minnesota Press, Minneapolis.

STOCKING, G. W. JR. (1965): On the limits of 'presentism'and 'historicism'in the historiography of the behavioral sciences. Journal of the History of the Behavioral Sciences, 1(3), 211-218.

Strathern, M. (2004): Partial connections. Altamira, Walnut Creek.

Tilley, C. Y. (1994): A phenomenology of landscape : places, paths, and monuments. Berg, Oxford.

Toscano, A. (2006): The theatre of production. Palgrave Macmillan, Nueva York.

VArelA, F.J. (1991): Organism: A meshwork of selfless selves. Organism and the Origin of Self(A.I. Tauber, Ed.), Springer, Dordrecht: 79-107.

Viveiros de CAstro, E. (2007): Filiação intensiva e aliança demoníaca. Novos Estudos-CEBRAP, (77): 91-126.

Viveiros de CAstro, E. (2010): Metafisicas canibales: Lineas de antropologia postestructural. Katz, Buenos Aires. 
Viveiros de Castro, E. (2011): Perspectival anthropology and the method of controlled equivocation. Tipiti: Journal of the Society for the Anthropology of Lowland South America, 2(1): 1.

Wagner, R. (1991): The fractal person. Big Men and Great Men: personifications of power in Melanesia (M. Godelier y M. Strathern, eds.), Cambridge University Press, Cambridge.

Watson, J. (2009): Guattari's Diagrammatic Thought: Writing Between Lacan and Deleuze. Continuum, Londres.

Webmoor, T. (2007): Un giro más tras el "giro social”. El principio de la simetría en arqueología. Complutum, 18: 296-304.

Webmoor, T.A. (2008): Reconfiguring the archaeological sensibility: Mediating heritage at Teotihuacan, Mexico. Tésis inédita, Archaeology Department, Stanford University.

Witmore, C. (2007): Arqueología simétrica: Un manifiesto breve. Complutum, 18: 305-313.

Witmore, C. (2005): Multiple field approaches in the mediterranean: revisiting the Argolid exploration project. Tésis inédita, Archaeology Department, Stanford University.

YANAI, T. (2002): Atravesar zonas de indiscernibilidad de identidades. América Latina: Historia y Sociedad, 202: 119-132.

ZAERA-Polo, A. (2008): The politics of the envelope: a political critique of materialism. Volume, 17: 76-105.

ŽIžEK, S. (2004). Organs without bodies: Deleuze and consequences. Routledge, Nueva York.

Zourabichvili, F. (2003): Le vocabulaire de Deleuze. Ellipses, París. 